\title{
Pengaruh Model Pembelajaran Visual Auditory Kinesthetic (Vak) Terhadap Hasil Belajar Bahasa Indonesia Siswa Kelas IV SDN 20 Woja
}

\author{
${ }^{1}$ Intan Nargis, ${ }^{2}$ Ida Ermiana, ${ }^{3}$ Heri Setiawan \\ $12{ }^{3}$ Program Studi PGSD, FKIP-Universitas Mataram \\ Email: intannargis2@gmail.com
}

\begin{abstract}
THE EFFECT OF VISUAL AUDITORY KINESTHETIC (VAK) LEARNING MODEL FOR INDONESIAN LEARNING OUTCOMES OF CLASS IV STUDENTS OF SDN 20 WOJA. This research aims to determine the effect of Visual Auditory Kinesthetic (VAK) for Indonesian Learning Outcomes of Class IV Students of SDN 20 Woja. The type of research used is Quasi Eksperimental Design of Nonequivalent Control Group Design type. The sampling technique used is purposive sampling. The population in this research amounted to 39 students. Data collection techniques used are tests and documentation. The research instruments used are learning outcomes tests and documentation sheets. The normality test is carried out by calculate the data in the form of Indonesian learning outcomes pre-test and post-test use kolmogrov smirnov formula with sig 5\% $(0,05)$ level then after the data is normally distributed homogeneity test was carried out from post-test outcomes calculation, then hypothesis test was carried out with $t$-test use student post-test data calculations. The results of data analysis obtained score sig 2 tailed as big as 0,012 whose score is less than 0,05 , then based on the research hypothesis, if score sig 2 tailed $\leq 0,05 \mathrm{t}$-tabel then Ho rejected and $\mathrm{H}_{\mathrm{a}}$ accepted. This shows that there is an effect of Visual Auditory Kinesthetic (VAK) for Indonesian Learning Outcomes of Class IV Students of SDN 20 Woja academic year 2020/2021. The results of this research are expected to be submitted as a reference in further research, but in different subjects.
\end{abstract}

Keywords: Visual Auditory Kinesthetic (VAK), Learning Outcomes

\begin{abstract}
Abstrak
Penelitian ini bertujuan untuk mengetahui pengaruh Model Pembelajaran Visual Auditory Kinesthetic (VAK) Terhadap Hasil Belajar Bahasa Indonesia Siswa Kelas IV SDN 20 Woja. Jenis penelitian yang digunakan ialah Quasi Eksperimental Design tipe Nonequivalent Control Group Design. Teknik pengambilan sampel yang digunakan adalah purposive sampling. Populasi pada penelitian ini berjumlah 39 siswa. Teknik pengumpulan data yang digunakan adalah tes dan dokumentasi. Instrument penelitian yang digunakan adalah tes hasil belajar dan lembar dokumentasi. Uji normalitas dilakukan dengan perhitungan data berupa hasil belajar bahasa Indonesia pre-test dan post-test menggunakan rumus kolmogrov smirnov dengan taraf sig 5\% $(0,05)$ kemudian setelah data berdistribusi normal dilakukan uji homogenitas yang diperoleh dari hasil perhitungan post-test, selanjutnya dilakukan uji hipotesis dengan uji $t$ menggunakan perhitungan data post-test siswa. Hasil analisis data didapatkan nilai sig 2 tailed sebesar 0,012 yang nilainya kurang dari 0,05, maka berdasarkan hipotesis penelitian, jika nilai sig 2 tailed $\leq 0,05$ t-tabel maka Ho ditolak dan $\mathrm{H}_{\mathrm{a}}$ diterima. Hal ini menunjukkan bahwa ada pengaruh Model Pembelajaran Visual Auditory Kinesthetic (VAK) Terhadap Hasil Belajar Bahasa Indonesia Siswa Kelas IV SDN 20 Woja Tahun Pelajaran 2020/2021. Hasil penelitain ini diharapkan dapat diajukan sebagai acuan dalan penelitian selanjutnya, namun dalam mata pelajaran yang berbedabeda.
\end{abstract}

Kata kunci : Visual Auditory Kinesthetic (VAK), Hasil Belajar

\section{PENDAHULUAN}

Hasil observasi yang dilakukan dikelas IV SDN 20 Woja diketahui bahwa aktivitas belajar pada pembelajaran terpadu belum optimal, hal ini disebabkan karena dalam kegiatan pembelajaran guru hanya menjelaskan konsep yang ada pada buku ajar, selain itu juga siswa lebih banyak mendengarkan, mencacat penjelasan guru serta kurang aktif dalam proses belajar mengajar, terutama dalam kegiatan diskusi, tanya jawab dan mengungkapkan pendapat, disisi lain Guru masih menggunakan metode ceramah, tidak menggunakan strategi, metode maupun model pembelajaran yang kreatif, sehingga sebagian kecil siswa kurang antusias mengikuti proses pembelajaran dan hal itu menyebabkan siswa cepat bosan dalam mengikuti proses pembelajaran. Alasan tersebut didasari karena minimnya sarana dan prasarana pendukung bagi guru di SDN 20 Woja.

Model pembelajaran yang digunakan sebagai pedoman dalam merencanakan suatu pembelajaran dan untuk menentukan perangkat pembelajaran lainnya yang diperlukan dapat 
tercapai. Guru diharapkan dapat mengkomunikasikan suatu konsep kepada siswa dengan baik agar dapat dipahami dan dikuasai sepenuhnya oleh siswa, akan tetapi tidak semua siswa dapat menguasai konsep secara baik dan memuaskan, karena proses pembelajaran dan interaksi edukatif yang berbeda-beda, oleh karena itu perlu disesuaikannya model pembelajaran dengan kebutuhan dan kondisi siswa untuk menciptakan peran aktif dan hasil belajar siswa yaitu dengan penerapan model yang bervariasi.

Salah satu model pembelajaran yang dapat digunakan yaitu dengan model pembelajaran visual, auditory, dan kinestethic (VAK).

\section{METODE}

Penelitian yang dilakukan adalah penelitian eksperimen. Menurut Sugiyono (2018:72) bahwa metode penelitian eksperimen merupakan metode penelitian yang digunakan untuk mencari pengaruh perlakuan tertentu terhadap yang lain dalam kondisi yang terkendalikan. Jenis penelitian ini adalah Quasi Eksperimental Design tipe Nonequivalent Control Group Design. Teknik pengumpulan data dalam penelitian ini menggunakan tes dan dokumentasi. Populasi dalam penelitian ini yaitu siswa kelas IV SDN 20 Woja. Instrument pengumpulan data dalam penelitian ini menggunakan tes hasil belajar dan lembar dokumentasi. Teknik analisis data menggunakan uji normalitas, uji homogenitas dan uji hipotesis.

\section{HASIL DAN PEMBAHASAN \\ Hasil \\ Data Hasil Belajar Bahasa Indonesia}

Nilai rata-rata pre-test hasil belajar bahasa Indonesia siswa kelas ekperimen yaitu 51,19 dan kelas kontrol yaitu 45,55 Sedangkan nilai rata-rata post-test hasil belajar bahasa Indonesia kelas eksperimen adalah 81,42 dan kelas kontrol yaitu 74,44. Adapun data hasil pre-test dan posttest untuk hasil belajar bahasa Indonesia pada kelas eksperimen dan kelas control dapat dilihat pada tabel berikut:

Tabel 4.1 hasil pre-test dan post-test siswa

\begin{tabular}{llllll}
\hline Kelompok & $\begin{array}{c}\text { Jumlah } \\
\text { Siswa (N) }\end{array}$ & Tes & $\begin{array}{c}\text { Nilai } \\
\text { Tertinggi }\end{array}$ & $\begin{array}{l}\text { Nilai } \\
\text { Terendah }\end{array}$ & Rata-rata \\
\hline Eksperimen & 21 & Pre tes & 70 & 40 & 51,19 \\
\hline Kontrol & 81 & Pos tes & 100 & 70 & 81,42 \\
\hline & Pre tes & 65 & 35 & 45,55 \\
\hline
\end{tabular}

Berdasarkan tabel di atas, dapat diketahui bahwa hasil pre-test kelas eksperimen dan kelas kontrol memiliki kemampuan yang tidak jauh berbeda. Dari data tersebut juga terlihat bahwa hasil belajar siswa kelas eksperimen setelah diberikan perlakuan (post-test) berupa penggunaan model pembelajaran Visual Auditory Kinestetik (VAK) dengan hasil lebih baik dan untuk nilai rata-rata siswa kelas eksperimen setelah diberikan perlakuan lebih baik.

Sedangkan hasil belajar siswa kelas kontrol (post-test) yang tidak diberikan perlakuan dengan menggunakan model pembelajaran Visual Auditory Kinestetik (VAK) mendapatkan nilai sedikit rendah maupun dengan nilai rata-ratanya yang tidak diberikan perlakuan. Berdasarkan hasil tersebut, dapat disimpulkan bahwa adanya perbedaan antara nilai rata-rata siswa kelas eksperimen dan kelas kontrol setelah diberikan perlakuan yang berbeda. Untuk hasil data pre-test dan post-test kelas eksperimen maupun kelas control.

\section{Hasil Uji Normalitas Data}

Perhitungan uji normalitas data menggunakan bantuan aplikasi SPSS 21 for windows. Dari perhitungan SPSS diperoleh nilai signifikansi untuk hasil pre-test kelas kontrol sebesar 0,073 lebih besar dari 0,05 dan kelas eksperimen sebesar 0,098 lebih besar dari 0,05. Kemudian untuk hasil post-tets, kelas Kontrol memperoleh nilai signifikan sebesar 0,069 lebih besar dari 0,05 dan kelas eksperimen memiliki nilai 0,057 lebih besar dari 0,05. Berdasarkan nilai yang yang diperoleh masing-masing hasil pre-test dan post-test baik dari kelas eksperimen kelas kontrol, semua nilai signifikansi tersebut lebih besar dari 0,05, Sehingga dapat disimpulkan bahwa data penelitian ini berdistribusi dengan normal.

\section{Hasil Uji Homogenitas Data}

Hasil penelitian yang dianalisa menggunakan SPSS 21, dapat dilihat bahwa hasil perhitungan nilai post-test sebesar 0,641 . Nilai ini lebih besar dari 0,05 sehingga dapat disimpulkan bahwa data penelitian ini bersifat homogen.

\section{Hasil Uji Hipotesis Data}

Dapat dilihat sig.2 tailed $<0,05$ yaitu 0,012 dengan derajat kebebasan $37(21+18=39-2=37)$. 
Sesuai dengan kriteria pengujian hipotesis yaitu sig. 2 tailed $<0,05$ maka $\mathrm{H}_{\mathrm{a}}$ diterima dan $\mathrm{Ho}$ ditolak. Hal ini menunjukkan bahwa adanya pengaruh model pembelajaran visual auditory kinestetik (VAK) terhadap hasil belajar bahasa Indonesia siswa kelas IV SDN 20 Woja.

\section{Pembahasan}

Penelitian ini merupakan penelitian Quasi Eksperimental yang dilakukan untuk melihat pengaruh suatu perlakuan tertentu dengan keadaan yang disengaja. Keadaan yang disengaja dalam penelitian ini berupa variabel bebas, variabel bebas dalam penelitian ini adalah model pembelajaran visual auditory kinestetik (VAK) dan variabel terikatnya hasil belajar bahasa Indonesia. Variabel independen (terikat) merupakan variabel yang mempengaruhi atau yang menjadi sebab perubahannya atau timbulnya variabel terikat (dependent) (Sugioyono, 2018:61). Sedangkan variabel terikat (dependent variable) merupakan variabel yang mempengaruhi atau yang menjadi akibat, karena adanya variabel bebas (Sugiyono, 2018:61). Penelitian ini diawali dengan pemberian pre-test pada kelas eksperimen dan kelas kontrol dengan tujuan melihat kemampuan awal siswa. Rata-rata nilai pre-test kelas eksperimen sebesar 51,19 sedangkan untuk kelas kontrol sebesar 45,55. Hasil ini menunjukkan bahwa kedua kelas memiliki kemampuan awal yang relative sama, sehingga dapat dilanjutkan untuk pemberian perlakuan. Peneliti memberikan perlakuan dengan menggunakan model pembelajaran visual auditory kinestetik (VAK) pada pembelajaran bahasa Indonesia di kelas eksperimen sebanyak satu kali pertemuan kemudian di kelas kontrol melakukan kegiatan pembelajaran yang sama namun tidak diberikan perlakuan dan hanya menggunakan model klasikal.

Setelah memberi perlakuan peneliti memberikan post-test pada kelas eksperimen dan kelas kontrol yang bertujuan untuk melihat pengaruh atau perbandingan hasil belajar bahasa Indonesia siswa antara kelas yang diberikan perlakuan menggunakan model pembelajaran visual auditory kinestetik (VAK) atau eksperimen dengan kelas kontrol yang tidak diberikan perlakuan. Sehingga lama proses pengumpulan data yang dilakukan mulai dari pre-test hingga post-test ialah sebanyak dua hari. Pemberian perlakuan dengan menggunakan model pembelajaran visual auditory kinestetik (VAK) pada kelas eksperimen pada pembelajaran bahasa Indonesia tema "Pahlawanku" dapat membantu siswa menyelesaikan soal-soal terkait cerita nonfiksi. Hal tersebut dilihat dari nilai rata-rata yang dihasilkan oleh kelas eksperimen dan kelas kontrol pada pelaksaan post-test masing-masing adalah 81,42 dan 74,44. Selain itu, nilai tertinggi untuk kelas eksperimen adalah 100 dan terendah 70. Sedangkan pada kelas kontrol nilai tertinggi 90 dan terendah 65. Hasil ini menunjukan adanya perbedaan antara nilai ratarata kelas eksperimen dan kelas kontrol. Hal ini dimungkinkan karena adanya perbedaan perlakuan yang diberikan pada kedua sampel tersebut. Perlakuan yang diberikan di kelas eksperimen adalah perlakuan khusus yaitu dengan menerapkan model pembelajaran visual auditory kinestetik (VAK) dalam proses pembelajaran, sedangkan di kelas kontrol tidak adanya perlakuan seperti pada kelas eksperimen atau menggunakan model klasikal.

$$
\text { Berdasarkan proses perlakuan }
$$
pembelajaran yang diberikan peneliti kepada kelas eksperimen berupa video cerita nonfiksi tentang pahlawan nasional pangeran Diponegoro terlihat beberapa keadaan yang berbeda dari perlakuan pembelajaran kelas kontrol antara lain yang pertama yaitu seluruh siswa fokus memperhatikan video pembelajaran tersebut, yang kedua siswa dapat memperoleh informasi yang lebih jelas berupa cerita langsung perjuangan dari pahlawan nasional Pangeran Diponegoro, yang ketiga bisa menghemat waktu dan rekaman dapat diputar berulang-ulang. Hal tersebut terlihat ketika peneliti menjelaskan semua materi pembelajaran cukup dengan menayangkan video pembelajaran tersebut seluruh materi pembelajaran sudah tercakup didalamnya dan peneliti juga bias memutar kembali video tersebut pada bagian mana yang belum dilihat oleh siswa, keempat peneliti cukup dengan hanya menampilkan video pembelajaran dan diiringi dengan penjelasan singkat saja. 
Setiap model pembelajaran memiliki kelebihan dan kelemahan masing-masing, tidak terkecuali model pebelajaran VAK juga memiliki kelebihan dan kelemahan diantaranya: Kelebihan dari pembelajaran Visual, Auditory, Kinestethic (VAK) adalah sebagai berikut: 1). Pembelajaran akan lebih efektif karena mengkombinasikan ketiga gaya belajar, 2). Mampu melatih dan mengembangkan potensi siswa yang telah dimiliki oleh pribadi masingmasing, 3).Memberikan pengalaman langsung kepada siswa, 4). Mampu melibatkan siswa secara maksiamal dalam menemukan dan memahami suatu konsep konsep melalui kegiatan fisik seperti demonstrasi, percobaan, observasi, dan diskusi aktif, 5). Mampu menjangkau setiap gaya belajar anak, 6). Siswa yang memiliki kemampuan bagus tidak akan terhambat oleh siswa yang lemah dalam belajar. Karena maodel ini mampu melayani kebutuhan siswa yang memiliki kemampuan diatas ratarata (Budiyanto, 2016:99).

Kelemahan dari model pembelajaran Visual, Auditory, Kinestethic (VAK), yakni tidak banyak orang mampu mengkombinasikan ketiga gaya belajar tersebut, sehingga orang yang hanya mampu menggunakan satu gaya belajar, hanya akan mampu menangkap materi jika menggunakan metode yang lebih memfokuskan kepada salah satu gaya belajar yang di dominasikan.

Sebaliknya pada kelas kontrol mereka lebih banyak mendengarkan penjelasan dari guru kemudian menulis hasil yang didengarkan. Proses pembelajaran pada kelas kontrol mempunyai peningkatan hasil belajar bahasa Indonesia lebih rendah daripada kelas eksperimen, karena semua konsep materi diberikan oleh guru menyebabkan siswa pasif dan tidak termotivasi untuk belajar. Jadi perlu pembaharuan pembelajaran dalam menentukan dan menggunakan model pembelajaran untuk mempengaruhi siswa materi yang diajarkan sebagaimana proses pembelajaran yang menggunakan model pembelajaran visual auditory kinestetik (VAK) pada kelas eksperimen.

Setelah diperoleh data hasil post-test belajar siswa, peneliti selanjutnya melakukan uji hipotesis dengan menggunakan uji $t$ dengan bantuan program aplikasi SPSS versi 21, diperoleh hasil sig. 0,012 dengan taraf signifikansi $5 \%$, yang berarti $0,012<0,05$ yang berarti bahwa hipotesis nol (Ho) ditolak dan hipotesis alternatif $\left(\mathrm{H}_{\mathrm{a}}\right)$ diterima. Adapun $\mathrm{H}_{\mathrm{a}}$ dalam penelitian ini adalah ada pengaruh model pembelajaran visual auditory kinestetik (VAK) terhadap hasil belajar bahasa Indonesia siswa kelas IV SDN 20 Woja.

\section{KESIMPULAN}

Berdasarkan penelitian yang dilakukan pada siswa IV di SDN 20 Woja tentang pengaruh model visual auditory kinestetik (VAK) terhadap hasil belajar bahasa Indonesia dengan menggunakan data kuantitatif uji $t$, dengan bantuan program aplikasi SPSS versi 21, diperoleh hasil sig. 0,012 dengan taraf signifikansi 5\%, yang berarti $0,012<0,05$ yang berarti bahwa hipotesis nol (Ho) ditolak dan hipotesis alternatif $\left(\mathrm{H}_{\mathrm{a}}\right)$ diterima. Sehingga dalam penelitian ini $\mathrm{H}_{\mathrm{a}}$ diterima dan Ho ditolak yang dapat disimpulkan bahwa terdapat pengaruh model pembelajaran visual auditory kinestetik (VAK) terhadap hasil belajar bahasa Indonesia siswa kelas IV SDN 20 Woja tahun ajaran 2020/2021.

\section{SARAN}

Berdasarkan hasil penelitian yang dilakukan oleh peneliti dan dilihat dari kesimpulan diatas, maka peneliti mengajukan dan mengemukakan beberapa saran sebagai berikut:

\section{Bagi Guru}

Diharapkan dapat menggunakan berbagai jenis model atau media yang dapat digunakan untuk menunjang proses belajar dan mengajar di kelas sehingga pembelajaran dapat berlangsung lebih menyenangkan dapat memberikan motivasi kepada siswa untuk giat belajar.

2. Bagi Siswa

Penggunaan model visual auditory kinestetik (VAK) dapat memberikan pemahaman dan motivasi yang lebih cepat terhadap materi yang disampaikan guru. Serta meminta guru untuk menerapkan model pembelajaran dalam proses belajar mengajar. 
3. Bagi Sekolah

Diharapkan dapat meningkatkan mutu dan kualitas pembelajaran di sekolah, serta mendukung dan memfasilitasi guru untuk menggunakan model pembelajaran yang beragam agar pembelajaran dapat berlangsung dengan menarik sehingga dapat memberikan motivasi dan hasil belajar yang optimal kepada siswa.

4. Bagi Peneliti Lain

Hasil penelitain ini diharapkan dapat diajukan sebagai acuan dalan penelitian selanjutnya, namun dalam mata pelajaran yang berbeda-beda.

\section{UCAPAN TERIMA KASIH}

Penelitian ini dapat dilaksanakan dengan baik berkat bantuan dari berbagai pihak, untuk itu peneliti mengucapkan terimah kasih kepada kepala sekolah SDN 20 Woja serta guru-guru yang telah membantu dalam penelitian ini.

\section{DAFTAR PUSTAKA}

Budiyanto, A., K. 2016. Sintaks 45 Model Pembelajaran dalam Student Centred Learning (SCL). Malang: UMM

DePorter, B \& Hernacki, M. 2015. Quantum Learning: Membiasakan Belajar Nyaman dan Menyenagkan. Bandung: Kaifa PT Mizan Pustaka

Fathurrohman. 2015. Model-model Pembelajaran Inovatif. Yogyakarta: Ar-Ruzz Media

Huda, M. 2017. Model-model Pengajaran dan Pembelajaran. Yogyakarta: Pustaka Pelajar

Komarudin. 2000. Kamus Istilah Karya Tulis Ilmiah. Jakarta: Bumi Aksara

Purwanto. 2014. Evaluasi Hasil Belajar. Yogyakarta: Pustaka Belajar

Santosa. P .,dkk. (2007). Materi dan Pembelajaran Bahasa Indonesia SD. Jakarta: Universitas Terbuka.

Shohimin Aris. 2014. 68 Model Pembelajaran Inovatif dalam Kurikulum 2013. Yogyakarta: Ar-Ruzz Media

Sudjana, N. 1999. Dasar-dasar Proses Belajar Mengajar. Bandar Lampung : Universitas Lampung
Sugiyono. 2018. Metode Penelitian Pendidikan Kuantitatif Kualitatif dan $R \& D$. Bandung: Alfabeta.

Susanto, A. 2016. Teori Belajar dan Pembelajaran. Jakarta: Prenada Media Grup. 